\title{
The Market Comparisons Appraisal Effect on the Housing Boom Cycles
}

\author{
Donald C. Keenan \\ Université de Cergy Pontoise
}

\author{
Taewon Kim \\ California State University, Los Angeles \\ Daniel C. Lee \\ California State University, Los Angeles
}

There is a pattern of gradual price rises and noticeably more sudden price drops in the housing market. This is because, in an upmarket, the market comparisons approach of the standard real estate appraisal technique forces home loan underwriters to be reluctant to approve a bigger loan than what the contemporary market comparisons would indicate. On the other hand, in a down market, underwriters do not face any such restriction, and hence prices can drop to the level fully reflecting the declining market condition. The traditional extrapolation typically used to determine the "time" value adjustments needs to be used more cautiously.

Keywords: appraised value, asymmetry, boom-bust cycle, contract price, effective demand, housing market

\section{INTRODUCTION}

A great deal of empirical evidence attributes the boom and bust cycles of the U.S. housing market to easy credit. In the aftermath of the 2001 economic recession, which occurred in the middle of the most recent housing boom of 1997-2007, for example, easy mortgage loans helped create a vast run-up in prices, and the fastest price appreciation occurred in the areas where subprime mortgages were most widely available including California (Berkovec, Chang and McManus 2012, Pavlov \& Wachter 2011).

At one point, the Federal Reserve lowered the federal funds rate close to $0 \%$. Some studies, notably Taylor (2007), find that this low interest rate to be an essential factor, especially in the latter part of the housing boom. Others do not believe low interest rates were necessary of major importance in creating a housing boom (Dokko et al., 2011). Similarly, Feng, Kim, and Lee (2016) and Feng, Kim, and Lee (2017) did not find the conventional relationship between low mortgage rates or bond rates and housing prices during the 1999-2006 housing boom. Even if low interest rates may not have directly contributed to housing bubbles, there is abundant evidence that housing refinancing spurred by low rates contributed to a consumption boom in the early 2000s (Greenspan and Kennedy 2008).

In this paper, our aim is not to explain the relationship between the housing boom and interest rates but to explain a very different pattern in the rises and the falls in housing prices. We observe a pattern of very gradual housing appreciation on the one hand and a pattern of sudden and noticeably more rapid fall on the 
downside. The same pattern was quite noticeable in the latest boom-bust cycle in most cities in the U.S. In fact, we observe a similar, repeated pattern of very gradual housing appreciation on the one hand and the repeated pattern of sudden and rapid depreciation in all the boom-bust cycles since 1969 (Figure 1).

\section{FIGURE 1}

\section{LONG TERM HOUSING MARKET CYCLE PATTERNS}

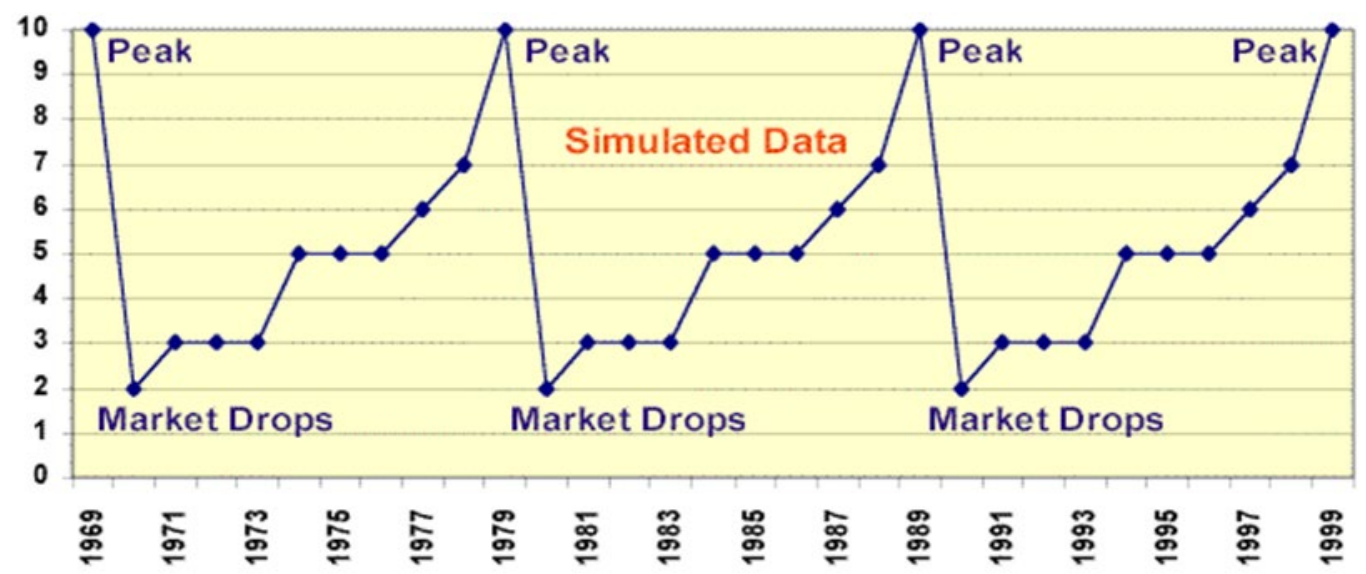

Source: St Louis Federal Reserve and Housing Update.com

Contrast this to the financial boom-bust cycles where the boom is not necessarily more gradual than the bust nor the bust so clearly more precipitous than the boom 1945-2010 (Figure 2). As we show below, the straightforward current practice of using past market comparable sales when doing standard real estate appraisal may be primarily responsible for this gradual appreciation and then a sudden drop in housing prices.

FIGURE 2

\section{U.S. ECONOMY: 1948-2011}

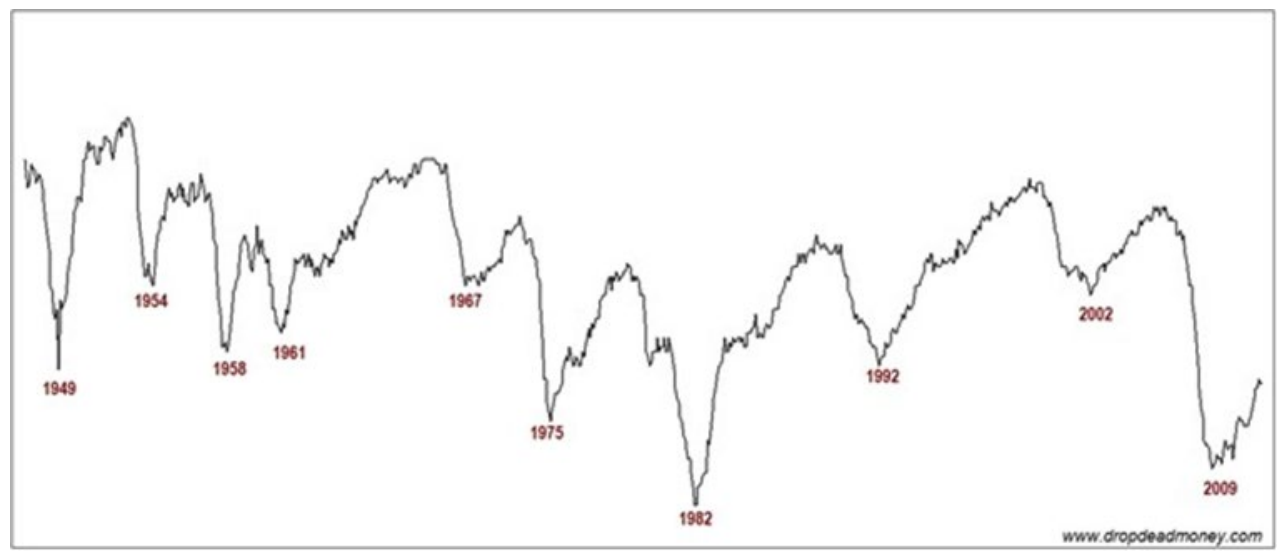

Source: U.S. Government statistics and Dropdeadmoney.com

The rest of the paper is organized as follows. In section II, we present these patterns using data from four big counties in Southern California and for the State of California as a whole, followed by one for a small city. In section III, we explain this asymmetry invoking a current appraisal practice known as the sales comparison approach (using the market comparable sales as the references). We also present further empirical evidence using housing data from cities nationwide. Section IV concludes the paper with further research suggestions. The literature review is spread out throughout the paper. 


\section{EMPIRICAL OBSERVATION}

In Figure 3 below, we construct housing price indexes for four counties of Los Angeles, Orange, Riverside, and San Diego, and one for the State of California as a whole to cover 1996 through 2012 by setting the value as of April 1996 at 100. Notice the very gradual price rises from 1996 through to the peak of the boom in 2007, followed by shorter and sudden price drops until the beginning of the next boom starting in 2012. Asymmetry in the rise and the fall of the prices is common to all the indexes, rising more slowly than falling. On a side note, the rising period is longer than the falling period.

FIGURE 3

COUNTIES OF LOS ANGELES, ORANGE, RIVERSIDE, SAN DIEGO, AND THE STATE OF CALIFORNIA

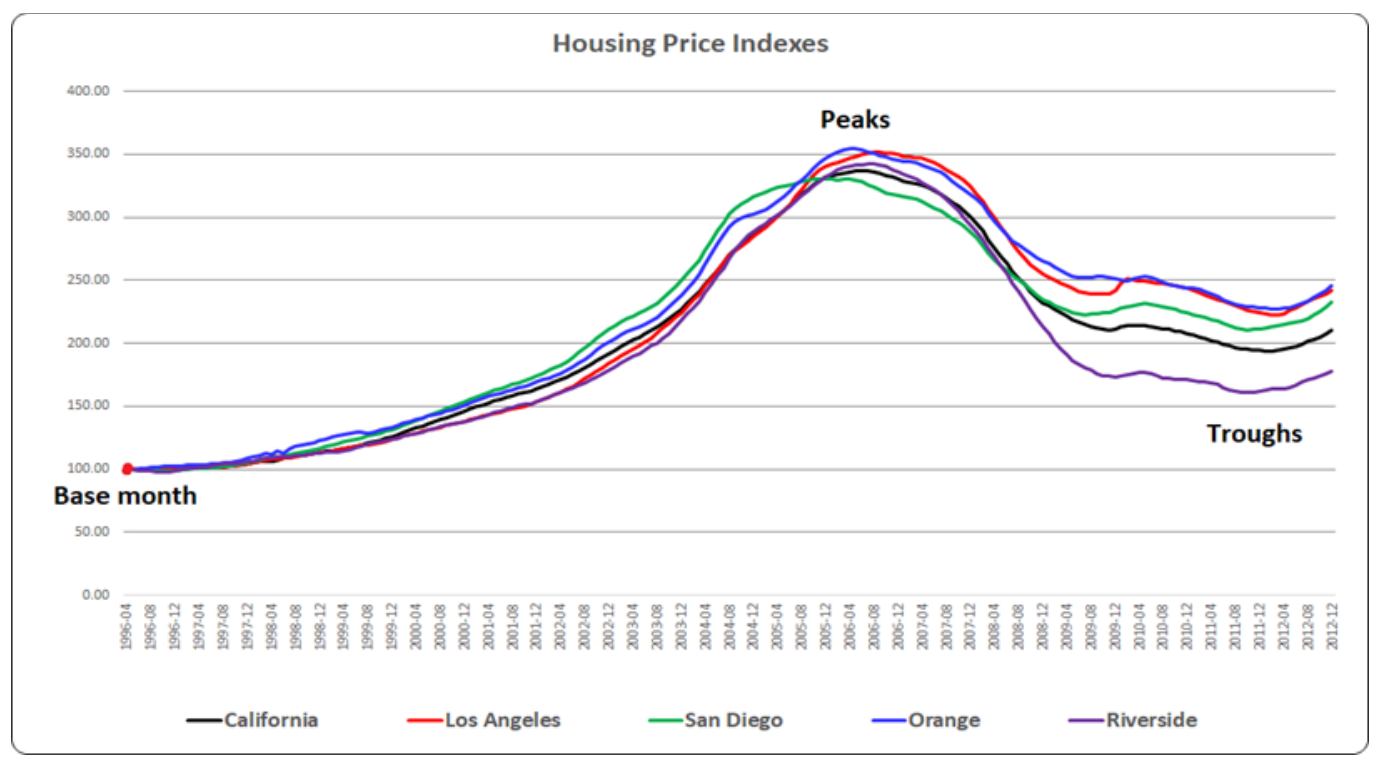

Source: zillow.com

Next, we choose a small city and look at its housing price movements for comparison purposes. Moreno Valley is a small city situated in the southeast of Southern California with a population of 52,000. We see a very similar pattern of asymmetry. The boom of 1996-2006 saw a more gradual rise than the speed of fall during $2006-2009$. 
FIGURE 4

CITY OF MORENO VALLEY

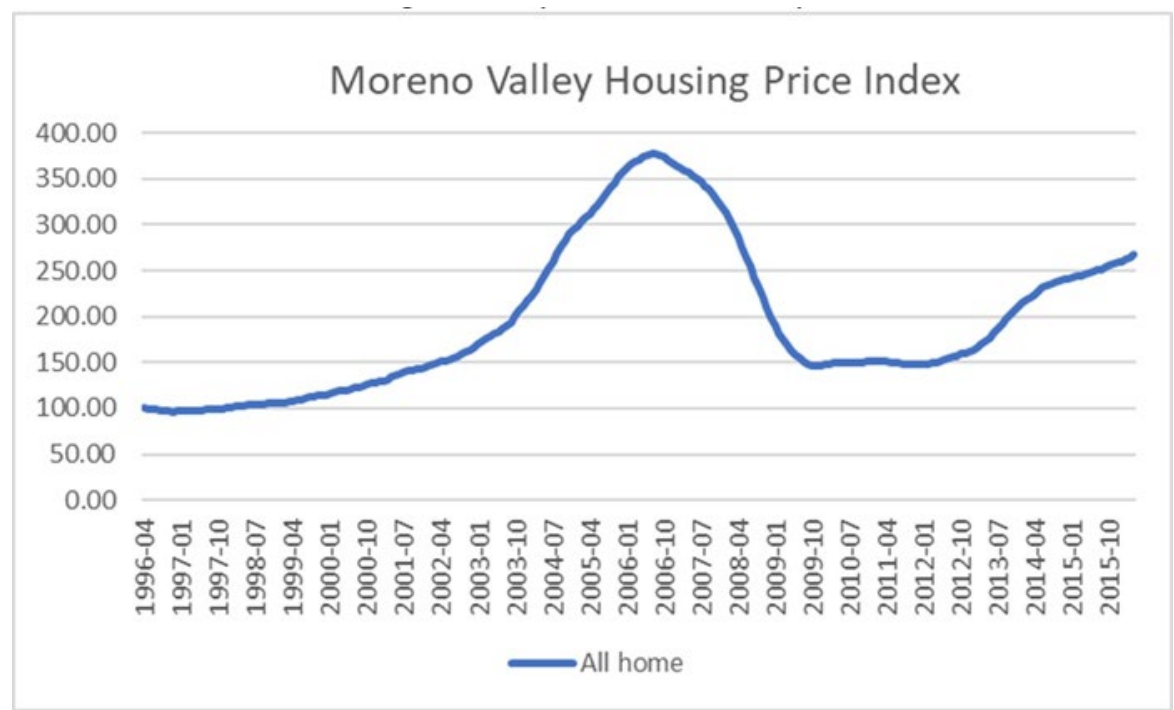

Source: zillow.com

\section{EXPLANATION OF THE ASYMMETRY}

\section{The Appraisal Practice}

As is well known, the market comparisons approach of the appraisal principles looks at the sale prices of comparable properties to estimate the value of the subject property. In this approach, therefore, the completed sale price of the comparable properties in the neighborhood is of paramount importance in determining the estimated appraisal value of the subject property. Mortgage underwriters then use this appraisal value in determining the loan amount to grant to the prospective buyer. It is easy to understand that in a rapidly rising market, why some properties may not "appraise out" for mortgage loans, hence dragging out an adjustment period for a correct appraisal.

However, this comparable sales approach makes room for modification for sales that occur under market conditions different from those applicable to the subject property and require adjustment for any differences that affect their values (often referred to as a "time" adjustment). Statistical tools such as regression analysis and extrapolation are typically used in determining precise "time" value adjustments.

As presented in the Appraisal of Real Estate (2013), an adjustment for market conditions is made if general property values have increased or decreased since the transaction dates. In other words, increases or decreases in property values in the market over time are the reason for the adjustment. The appraiser typically uses time as the basis for the adjustment. For example, in the same market area, one three-bedroom home with similar characteristics sold for $\$ 260,000$ three years ago and resold again last year for $\$ 250,000$. The average annual change for that comparable property is $1.92 \%$ per year $([(\$ 260,000$ $-\$ 250,000) / \$ 260,000] / 2)$.

Similarly presented The Student Handbook to the Appraisal of Real Estate (2014), "the rate of change in market value over time can be calculated ... on a straight-line basis ... for a property that sold in 2009 for $\$ 12$ million and resold in 2013 for $\$ 15$ million: Divide the difference between the original price $(\$ 12$ million) and the later price ( $\$ 15$ million) by the original price, and then divide that quotient by the elapsed time: $[(\$ 15,000,000-\$ 12,000,000) / \$ 12,000,000] / 4=+25 \% / 4=6.25 \%$ per year."

It is pretty clear that the appraisal industry practice allows adding an average appreciation value onto the prices of the comparable sales to improve the accuracy of the valuation result. However, it is only helpful when the market is in the straight-line appreciation stage. In a rapidly appreciating environment, especially in the bubbling stage, it will not help much. 
If the market value changes always behaved in a straight-line-like pattern, this practice will better reflect the market condition or "time" adjustment. Unfortunately, the empirical data, as illustrated in Figure 3 and 4, have proven that these were not how the market always performed. In Figure 4, we observe that in the initial stage of the boom markets (say, April 1996 to January 2002), all the indexes move upward in straightline-like patterns. When they reach the "bubbling stage," they started to move upward exponentially until reaching the peak of the bubbles. Then all the indexes began to fall dramatically.

These observations provided a warning to the appraisers. Even if they use the forward-looking approach and try to conduct the "time" adjustment in their appraisal practice, they will not be able to make accurate adjustments for "time." They will not be able to foresee that the market has changed the regime and is moving into the bull market's bubbling stage. By continuously using the straight-line adjustments for their value estimate to the subject property, they will under-estimate the market value. In the mortgage industry, when the appraised value is lower than the contract price, the lender will use the appraised value to determine the approved loan amount, which means the buyer will need to put up more cash to complete the deal. If the buyer does not have enough savings, the transaction will fail.

Moreover, today the Federal law has stipulated that every buyer is entitled to receive a copy of the appraisal report. If the buyers realize that they are paying more than the appraised value, they tend to get cold feet and may back out of the deal. In some states, in addition to the typical loan contingency clause, the standard purchase contract includes a contingency clause allowing the buyer to legally back out of the purchase offer if the appraised value is lower than the contract price. In California, as an example, the second page of the standard "California Residential Purchase Agreement" by the California Association of Realtors includes an appraisal contingency clause to give the buyer the right to legally back out from the purchase offer if the appraised value is lower than the contract price.

As a result, this deal-breaking practice will reduce the effective demand. This, in turn, will partially deflate the market bubbles because some sellers will have no choice but to lower the listing prices to make the sales happen if they do not have enough staying power. It has become evident that the typical appraisal practice prevents actually observed housing prices from rising overmuch when the market has reached the bubbling stage.

On the other hand, in the bust period, when the market price of housing declines dramatically, the similar problem of house appraisal poses little effect to slow down the downward market momentum. In the lending practice, especially in a bearish market, the lender will become even more conservative and use the lower of the appraised and the contract price to determine the approved loan amount in order to control the default risk. When the appraised values are lower than the contract prices, the lenders will use the appraised values and reduce the loan amounts and give the buyers incentive to back out from the deals when they feel they have overpaid for the properties. Like what happens in the bubbling stage, the effective demand for properties will be reduced, which will depress the market prices even more. When the appraised values are higher than the contract prices, the lenders ignore the appraised values and use contract prices as the benchmark to determine the loan amounts. In this situation, the observed transactions will follow the underlying market (i.e., the contract) prices down in a one-to-one fashion. The contract prices will become new comparable sales for appraisers to use in the next assignment. This repetition causes observed house prices to behave asymmetrically, rising more slowly than they fall, even if there is no asymmetry in the natural movements of the underlying market prices because the appraisal prices will impose pressure on the upward price momentum. In contrast, they impose no effect on the downward price momentum.

This asymmetrical phenomenon is quite general and will apply to almost any underlying housing market model. Geanakoplos \& Zame (2014), while abstract, has designed a framework to treat the realities of the housing market.

No default ever occurs in the traditional framework with uncertainty and complete markets (i.e., the Arrow-Debreu model). In this market, all agents possess perfect foresight of what will happen, contingent on the state that transpires, and so can and do make plans that they can always fulfill: they are implicitly facing infinite punishments for defaulting. However, this is not a good reflection of current practice, particularly not in the housing market. There has been a recent development of full-fledged general equilibrium models but ones that consider that borrowers will default if they have no reason not to. As a 
result, the market has to manage the risk by requiring collateral on the mortgage, inevitably using the house itself. Keenan and Kim (2013) design an idealized appraisal method for residential housing using a filtering approach (hereafter the Keenan-Kim-filtering model).

In the simplest economy with just one durable, the house, then the level of collateral will typically be selected endogenously by the model's setup, so that of the many loan types possible, only one will be actively traded. For the model to be interesting, there should be heterogeneity among consumers; in the case of a durable consumption good like housing, that is most conveniently captured by some consumers having a greater taste for housing than do others. Because such consumers can borrow on the margin with loans collateralized by the house itself, this drives up the price of the house from what it would otherwise be. However, when a state emerges where these house-loving consumers suffer a sufficient income loss, the default occurs. Then the housing price will fall precipitously, much more than if there had been perfect forward markets, where they could have diversified away all such risk in advance. Thus the Keenan-Kim filtering model delivers more significant variability in house prices than does the traditional one. In this paper, we show, though, that the rise in house prices is hobbled by appraisal practices, whereas the fall in prices is not similarly constrained. The only advantage of the collateral model presented, other than its greater institutional realism for housing markets, is that it provides a general environment of volatile housing prices, one ideal for seeing the asymmetric effects of appraisal practices.

\section{Additional Empirical Observation}

There is well-established literature on testing for asymmetry of economic and financial time. This paper randomly picked six cities out of the twenty fastest-growing cities and another six out of the twenty fastest shrinking cities identified by the U.S. Census Bureau. The list of these top twenty growing and shrinking cities is provided in Appendix A. We plotted the time series data of the residential median prices and per square foot values provided by the Zillow.com and use the same method to create price indexes for those twelve cities.

The time-series data for the six fastest-growing cities confirms our previous observations that housing appreciation is slower and takes longer to take effect than the fall. These cities are Raleigh, North Carolina; Orlando, Florida; Fort Collins, Texas; St. George, Utah; Greely, Colorado; and the affluent resort community of The Village of Palmetto Bay, Florida. Figure 6 illustrates the monthly median per square foot price between 04/1996 and 08/2016. This period covers a long housing boom between 1996 and 2006, a steep housing recession from 2006 to 2011 followed by another phase of appreciation. In all six cities, an overall appreciation takes longer and is somewhat more gradual than the drops. Note the idea of efficient markets hypothesis, where investors will use public information in their trading. The securities prices will reflect this underlying information as long as transaction costs are not too high. In the case of real estate, the current appraisal practice might render housing transactions costs to be not just high but prohibitive. Figures 7 and 8 showed the trajectories of the median price of all homes and the housing price indexes for the same six cities, respectively. Although not as evident as shown in Figure 6, we can still observe that the pattern remains almost the same. The speed of rising during the boom is slower than the fall during the bust for the same 1996-2016 period. 
FIGURE 6

THE MEDIAN VALUE PER SQUARE FOOT FOR THE SIX FASTEST-GROWING CITIES

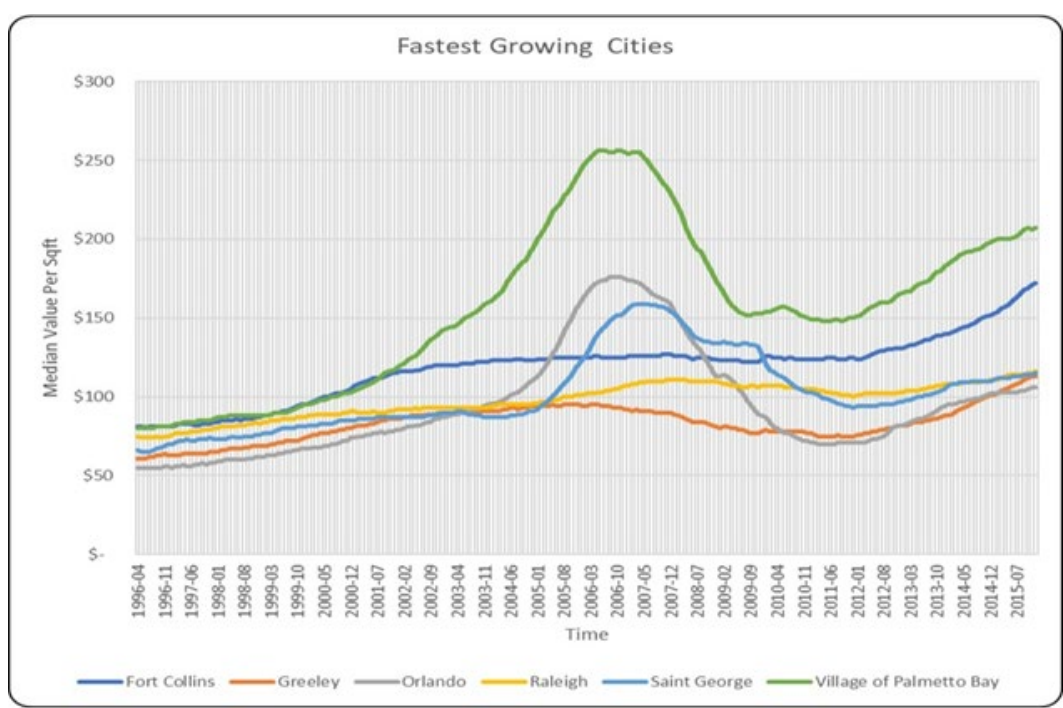

Source: zillow.com

FIGURE 7

THE MEDIAN PRICE OF ALL HOMES FOR THE SIX FASTEST GROWING CITIES

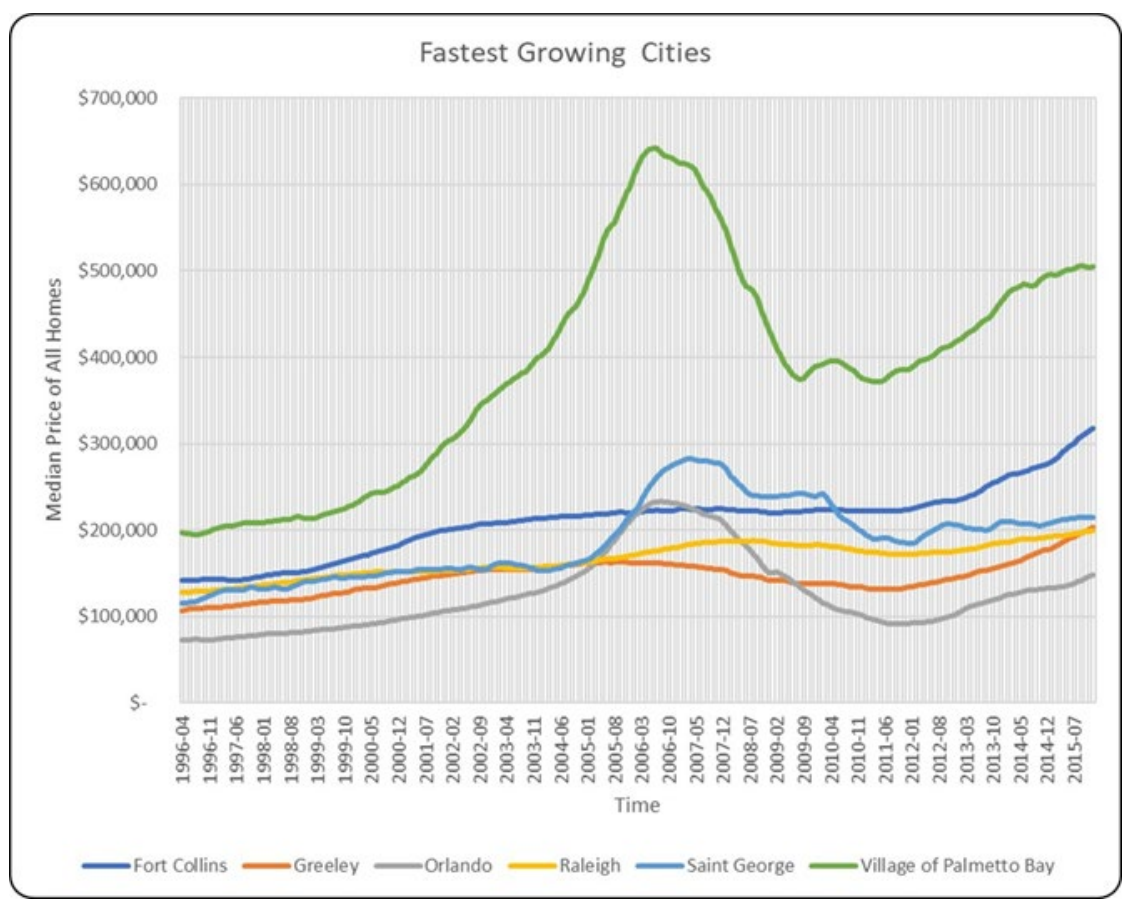

Source: zillow.com 


\section{FIGURE 8}

\section{HOUSING PRICE INDEXES FOR THE SIX FASTEST GROWING CITIES}

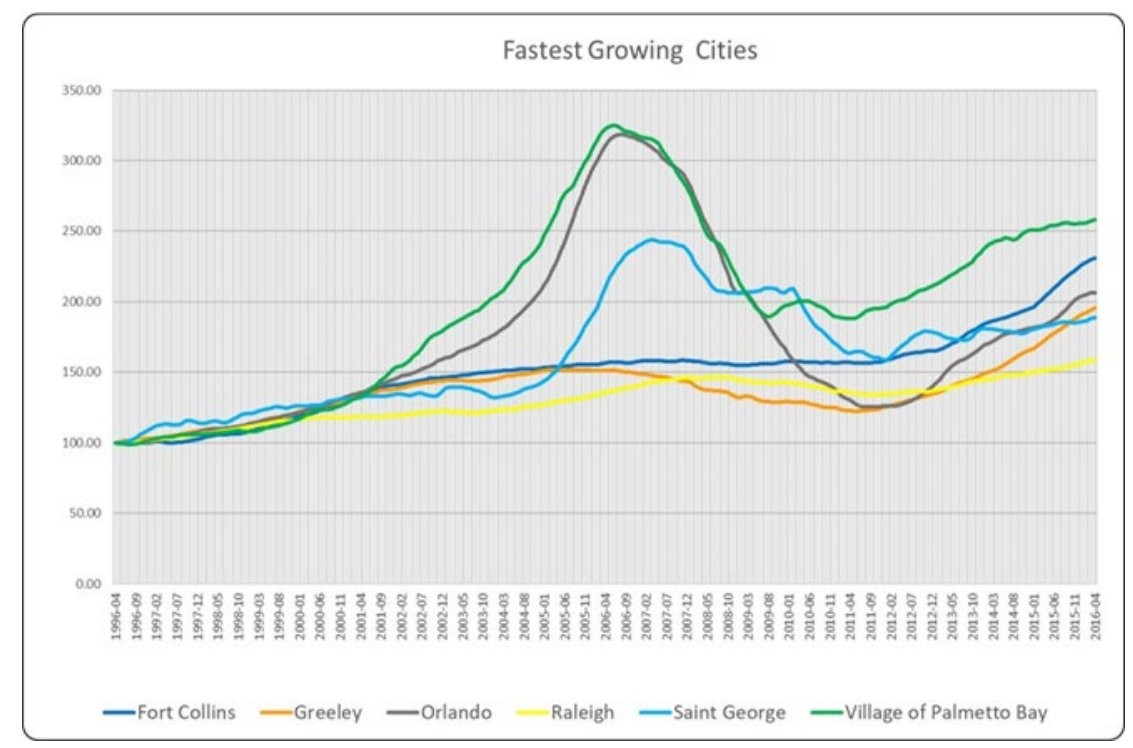

Source: zillow.com

As for the six shrinking cities, we observed that the markets were slow to rise. Even in the height of the housing boom, they still appreciated in a straight-line-like pattern (except for Sierra Vista-Douglas, Arizona). As a result, the market comparable sales approach is not much of a hindrance to loans being appraised out. So one would not expect an asymmetry between appreciation and depreciation. The shrinking cities are Flint, Michigan; Saginaw, Michigan; Albany, Georgia; Charleston, South Carolina; Sierra VistaDouglas, Arizona; and Kankakee, Illinois. We show the trajectories for the same period in Figures 9, 10, and 11 using per square foot housing price, median housing price, and constructed price indexes, respectively. Unfortunately, we observed no clear patterns of such asymmetry between the rise and the fall, unlike in the case of fast-growing cities, where such a phenomenon is evident.

\section{FIGURE 9}

\section{THE MEDIAN VALUE PER SQUARE FOOT FOR THE SIX FASTEST SHRINKING CITIES}

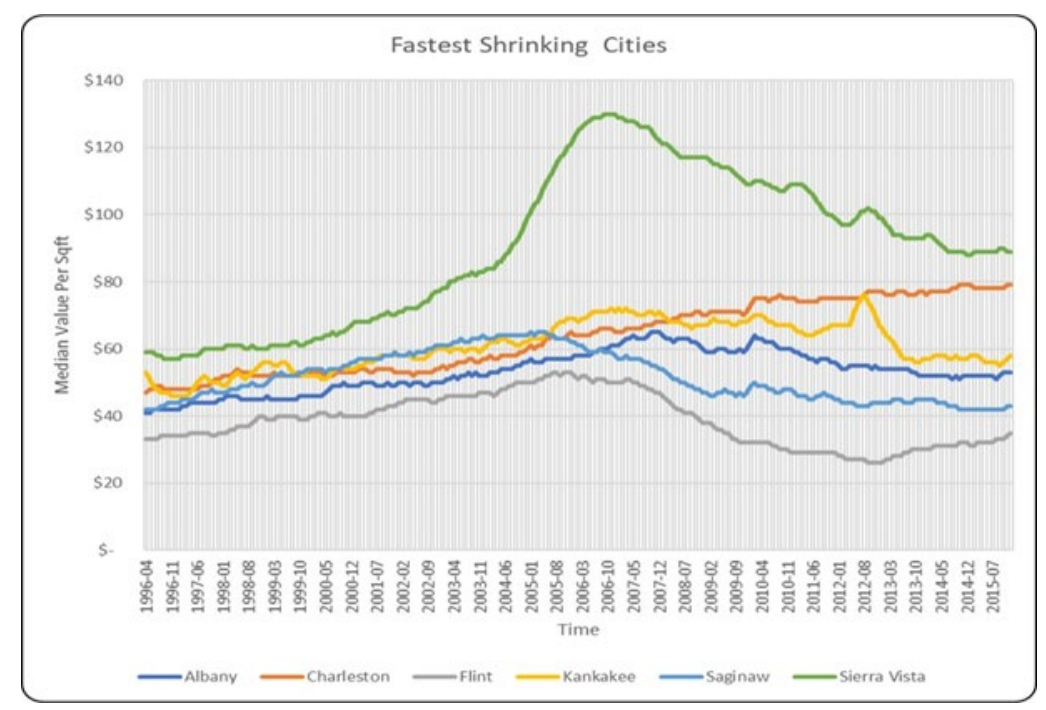

Source: zillow.com 
FIGURE 10

\section{THE MEDIAN PRICE OF ALL HOMES FOR THE SIX FASTEST SHRINKING CITIES}

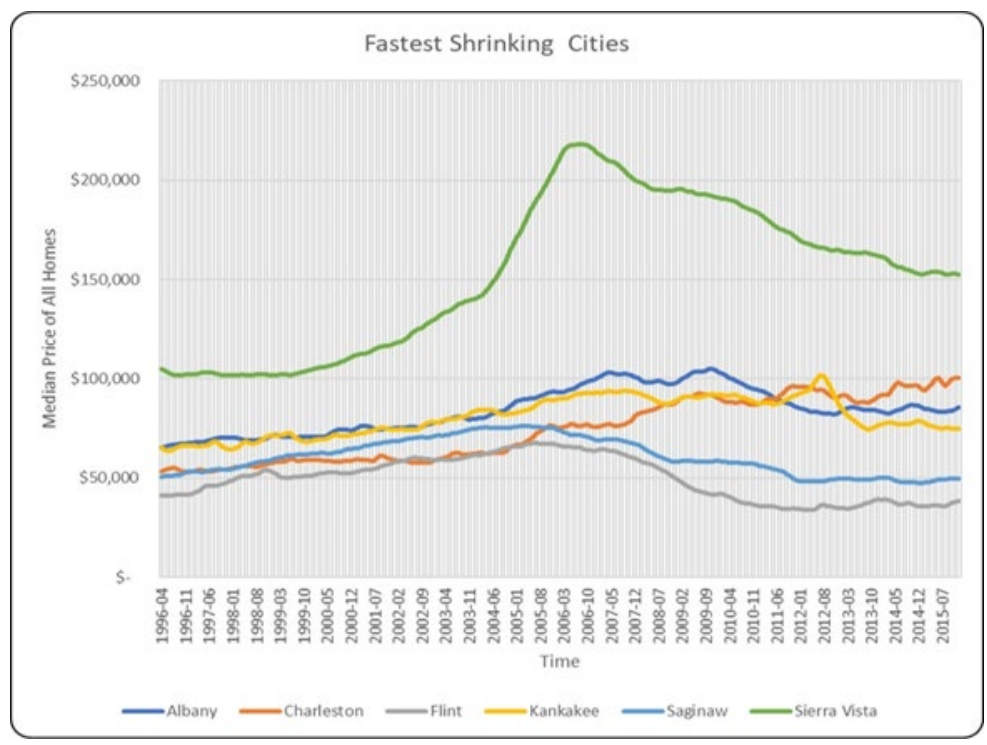

Source: zillow.com

FIGURE 11

HOUSING PRICE INDEXES FOR THE SIX FASTEST SHRINKING CITIES

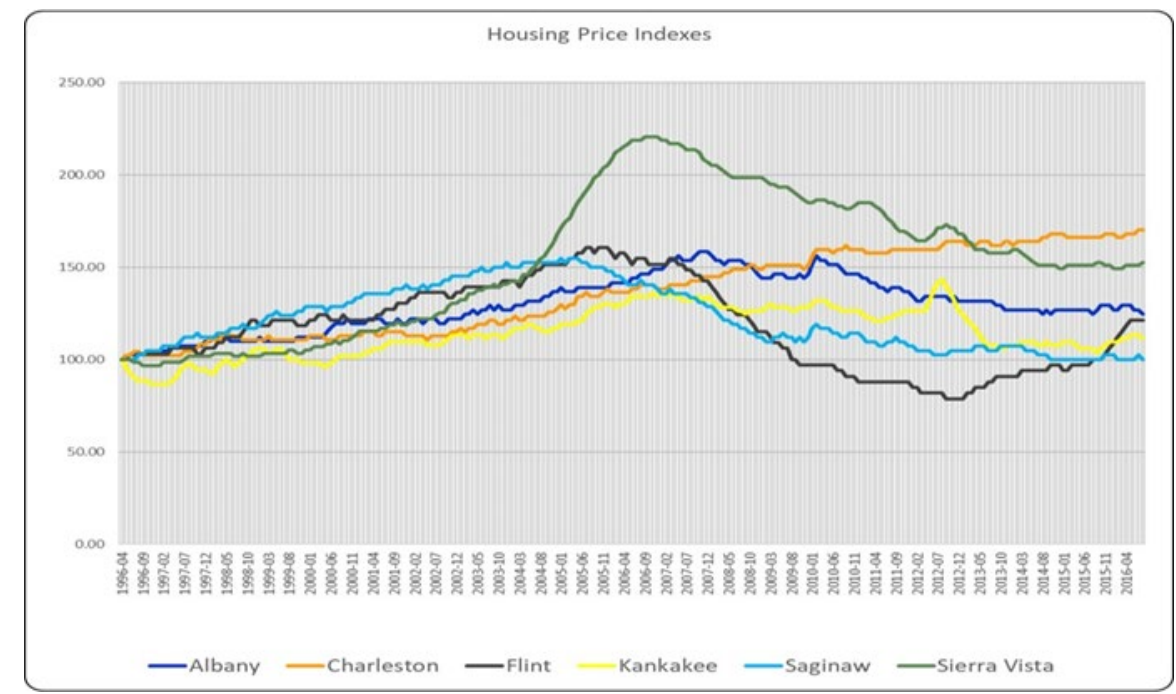

Source: zillow.com

\section{FURTHER RESEARCH SUGGESTIONS}

The subsequent research to be conducted along this theme of asymmetry is simulation. For example, we would like to explain why, even if a general pattern of slow appreciation and sudden drops seems to be common to most cities in general, the speed of price changes looks quite different. One prominent place to look for such an explanation is population growth in each city. The employment rate is another. For example, one could use a framework similar to those employed by Geanakoplos \& Zame (2014) or Gelain, Lansing \& Natvik (2015), estimate parameters, and find models that work best reproducing the actual house price movements. 
Similarly, some cities can be geographically more expandable than others. Los Angeles comes to mind in comparison with, say, San Francisco. Such geographic characteristics would also influence the speed of housing appreciation and depreciation (Kusisto 2016).

We want to make an interesting observation here. As housing prices started to bounce back at the end of the housing market crash, one might have expected the overall outstanding mortgage debt to go up accordingly. That did not happen this time around; the overall mortgage debt went down instead (Figure 12). One can only conjecture that after the crash, lenders started requiring more stringent lending terms, and as a result, the total credit could not go up even as prices were recovering. This credit crunch resulted in more cash put in the housing market on the part of buyers. There is much anecdotal evidence that this no-rise in total housing credit is due to many cash buyers starting to pour into the housing market during this period. One can conjecture that, especially in cities where much cash is used in property purchases by new immigration groups or others. Hence, buyers are not necessarily bound by property purchase value being appraised out by lenders, and housing appreciation would not be so gradual. In these places, the speed of appreciation in fact, could be just as steep as the market condition warrants.

FIGURE 12

\section{OUTSTANDING MORTGAGE DEBT}

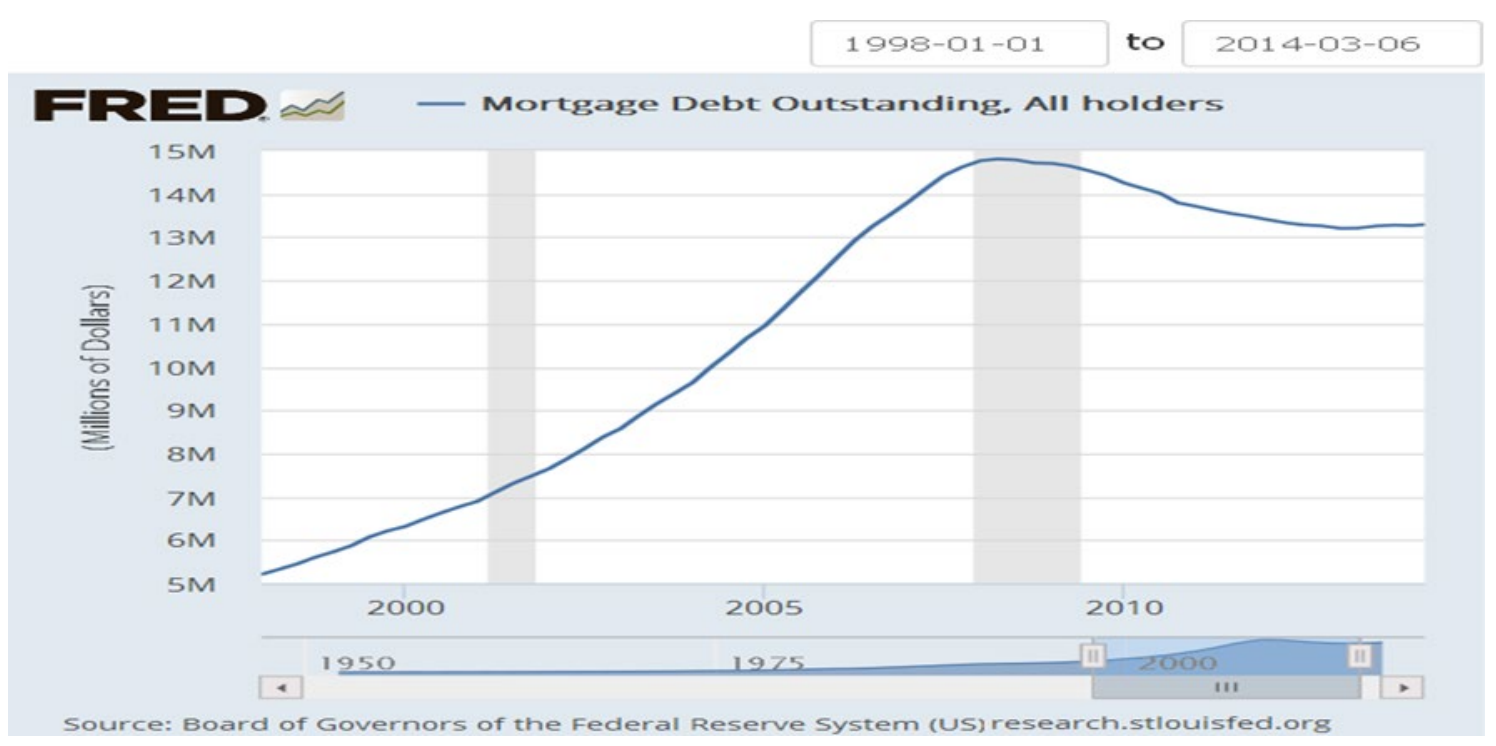

Suppose one can select fast-growing cities with evidence of a great deal of cash infusion (or below the national average loan to value ratio usage) and compare them to cities where cash is not much in use. In that case, we could secure more evidence that the cause of the asymmetry in question is the institutional appraisal practice. The result of this type of analysis could then be utilized in modifying home appraisal values in the rest of the country without having to wait for the actual market comparable sales to reflect current market conditions.

\section{ACKNOWLEDGEMENT}

We thank the College of Business and Economics, CSULA for supporting this research. 


\section{REFERENCES}

Berkovec, J., Chang, Y., \& McManus, D.A. (2012). Alternative lending channels and the crisis in U.S. housing markets. Real Estate Economics, 40(Special Issue 1), 8-31.

Dokko, J., Doyle, B.M., Kiley, M.T., Kim, J., Sherlund, S., Sim, J., \& Van Den Heuvel, S. (2011). Monetary policy and the global housing bubble. Economic Policy, 26(66), 237-287.

Feng, Y., Keenan, D.C., Kim, T., \& Lee, D.C. (2017). Housing Prices at the time of Q.E.s in California: Effect of Mortgage Rates. International Journal of Financial Research, 8(2), 1-6.

Feng, Y., Kim, T., \& Lee, D.C. (2016). Corporate bond yields, mortgage rates, and housing prices. Working paper.

Feng, Y., Kim, T., \& Lee, D.C. (2017). The Impact of Bond Yields on Housing Prices during the Time of Q.E.s. International Research Journal of Applied Finance, 8, 443-452.

Gelain, P., \& Lansing, K.J. (2013). House Prices, Expectations, and Time-Varying Fundamentals. Working Paper Series 2013-03. Federal Reserve Bank of San Francisco.

Gelain, P., Lansing, K.J., \& Natvik, G.J. (2015). Explaining the Boom-Bust Cycle in the U.S. Housing Market: A Reverse-Engineering Approach. Working Paper Series 2015-02. Federal Reserve Bank of San Francisco.

Goetzmann, W.N., Peng, L., \& Yen, J. (2012). The subprime crisis and the house price appreciation. Journal of Real Estate Finance and Economics, 44, 36-56.

Greenspan, A., \& Kennedy, J. (2008). Sources and uses of equity extracted from homes. Oxford Review of Economic Policy, 24(1), 120-144.

Pavlov, A., \& Wachter, S. (2011). Subprime lending and real estate prices. Real Estate Economics, 39, 117.

Rattermann, M. (2014). The Student Handbook to The Appraisal of Real Estate. The Appraisal Institute. Taylor, J.B. (2007). Housing and Monetary Policy. NBER Working Paper Series, 13682, 1-16.

The Appraisal Institute. (2013). Appraisal of Real Estate.

\section{APPENDIX: THE FASTEST GROWING AND SHRINKING CITIES IN USA FOR THE PERIOD 2010-2015}

Twenty Fastest Growing Cities From the U.S. Census Bureau

Houston, TX, Orlando, FL, Austin, TX, Raleigh, NC, Fort Myers, TX, Myrtle Beach SC, Naples, FL, Fort Collins, CO, Greely, CO, Crestview-Fort Walton Beach-Destin, FL, Charleston, WV, Fargo, ND, Daphne, AL, Bend, OR, Midland, TX, Auburn, AL, St. George, UT, Odessa, TX, Bismarck, ND.

\section{Twenty Fastest Shrinking Cities From the U.S. Census Bureau}

Charleston, SC, Youngstown, OH, Flint, MI, Rockford, IL, Saginaw, MI, Albany, GA, Rocky Mount, NC, Wheeling, OH, Johnstown, PA, Sierra Vista, AZ, Pittsfield, MA, Weirton, OH, Anniston, AL, Kankakee, IL, Decatur, IL, Cumberland, MD, Pine Bluff, AR, Ocean City, NJ, Danville, IL, Farmington, NM. 